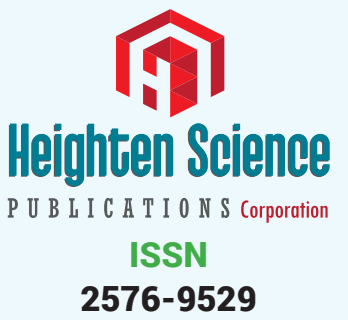

*Address for Correspondence: Dada SA, Nephrology Unit, Department of Medicine, Ekiti State University Teaching Hospital, Ado Ekiti, Ekiti State, Nigeria, Tel: +2348035141388; Email: ayokunle.dada@eksu.edu.ng

Submitted: 11 March 2019

Approved: 18 March 2019

Published: 28 March 2019

Copyright: @ 2019 Dada SA, et al. This is an open access article distributed under the Creative Commons Attribution License, which permits unrestricted use, distribution, and reproduction in any medium, provided the original work is properly cited

Keywords: Renal replacement therapy; Vascula access; End stage renal disease; Nigeria

Check for updates
Research Article

\section{Challenges of haemodialysis: A single centre experience in South West Nigeria}

\author{
Samuel Ayokunle Dada ${ }^{1 *}$, Adebukola Bidemi Ajite², Funmilayo \\ Abimbola Ibitoba', Awolowo Anthony Thomas ${ }^{3}$, Oluwamayowa \\ Esther Dada ${ }^{4}$ and Olabisi Olamide Deji-Dada ${ }^{5}$

\begin{abstract}
'Nephrology Unit, Department of Medicine, Ekiti State University Teaching Hospital, Ado Ekiti, Ekiti State, Nigeria

2Department of Paediatrics Nephrology, Ekiti State University Teaching Hospital, Ado Ekiti, Ekiti State, Nigeria

${ }^{3}$ Radio-diagnostic Department, Ekiti State University Teaching Hospital, Ado Ekiti, Ekiti State, Nigeria

${ }^{4}$ Department of Health Information Management, Ekiti State University Teaching Hospital, Ado Ekiti, Ekiti State, Nigeria

${ }^{5}$ Department of Family Medicine, Ekiti State University Teaching Hospital, Ado Ekiti, Ekiti State, Nigeria
\end{abstract}

\section{Abstract}

Background: Haemodialysis is the commonest method of Renal Replacement Therapy in Nigeria. Despite an advancement in the technicality and better understanding of haemodialysis, a number of complications are known to be associated with this procedure.

Objective: We aimed to highlight our experiences and share some of the uncommon complications encountered during haemodialysis and present the outcome of our patients.

Subjects and methods: A retrospective review of 101 patients during the last two years was done. Data extracted include: sociodemographic characteristic, aetiology of kidney disease, type of vascular access, intradialytic complication and outcome of treatment.

Results: The total number of dialysis session during the period was 823. Males constituted a higher proportion (64.4\%) and were found to be older than female patients 49.8 vs 42.8 years $(P=0.001)$

Majority (89.1\%) had chronic kidney disease while chronic glomerulonephritis was the main cause of CKD as seen in about $45 \%$ of the patient.

Due to the cost implication, only 2(1.98\%) were able to undergo 3 sessions of dialysis per week for up to 1 month.

Vascular access was femoral (66.3\%), internal jugular vein (25.7\%), while only $2 \%$ used Artero-venous-fistula and one patient had femoral vessel pseudoaneurysm from frequent cannulation.

The commonest complication was hypotension which was present in 15.8\%. Twenty-eight deaths were recorded, $44(43 \%)$ were either lost to follow up or absconded while $5 \%$ were transplanted at a referral centre.

Conclusion: Challenges of renal replacement therapy is overwhelming in our country due to poor human and financial resources. Early diagnosis and adequate government support are advocated.

\section{Introduction}

Renal Replacement Therapy (RRT), dialysis (haemodialysis and peritoneal dialysis) or renal transplantation is required when there is kidney failure. However, dialysis in either modality offers only a partial replacement of the kidney function. 
The availability of RRT is quite variable worldwide with the worst scenario in subSaharan Africa where only a small proportion of patients are on treatment due to poor socio-economic status, lack of trained health personnel among other factors [1-3]. In the developed countries, the economic consequences of RRT are equally challenging with the growth of dialysis programmes ranging between $6 \%$ and $12 \%$ [4].

Haemodialysis (HD) is the commonest method of renal replacement therapy among Nigerian patients with end-stage renal disease (ESRD). Though, the services are still predominantly urban and generally inaccessible to the poor rural patients. Despite a better understanding of the physiology of haemodialysis procedure and the technological advances in the field of nephrology, a number of complications are known to be associated with this form of RRT. This study was aimed at highlighting our experience in the recent 2years and also to share some of the complications encountered during dialysis and present the outcome of our patients.

\section{Subjects and Methods}

This is a retrospective review of case records and dialysis register of consecutive patients who underwent haemodialysis at the dialysis centre of Ekiti State University Teaching Hospital during the last two years (January 2015- December 2016). The dialysis centre usually gets referrals from nearby hospitals in Ekiti State and the surrounding states. Unstructured proforma was designed and used to extract data such as the sociodemographic characteristic, aetiology of acute kidney injury and chronic kidney disease, type of vascular access, intradialytic complication and outcome of treatment.

Diagnosis of the patient was based mainly on clinical evaluation, laboratory findings and few supported by histological reports of renal biopsy.

All patients who were on maintenance haemodialysis for ESRD during the specified period were included in the study. However, patients on transient haemodialysis such as those from abroad who underwent regular haemodialysis for a brief period before returning to their base were excluded from the study. Ethical clearance for the use of the record was obtained from the ethics and research committee of the hospital.

\section{Data analysis}

The data was analyzed with SPSS version 20. Continuous and categorical variables were analyzed with chi-square and student's T-test respectively. Charts and a table were drawn to present data.

\section{Results}

There were 101 patients who underwent haemodialysis between January 2015 and December 2016. During the period under review, 823 sessions were recorded. Males constituted a higher proportion (64.4\%) and were also found to be older than female patients (49.8 vs 42.8years, $\mathrm{P}=0.001$ ). Majority $(89.1 \%$ ) had chronic kidney disease (CKD) while only 11 patients had acute kidney injury (AKI) Table 1. Chronic glomerulonephritis was the main cause of CKD as seen in about $45 \%$ closely followed by hypertensive glomerusclerosis. Less common aetiological cause seen among the patients were analgesic nephropathy, sickle cell nephropathy, AKI that progress to CKD and unknown aetiology as shown in figure 1.

Almost all patients paid out of pocket while few benefitted from only six sessions paid for through their National Health Insurance Scheme (NHIS). Only 2(1.98\%) patients were able to undergo 3 sessions of dialysis per week for up to 1 month while $19(18.8 \%)$ could only do at most 2 sessions per week for the first 3 months.

The most frequently used vascular access route was femoral (66.3\%) followed by internal jugular vein in less than one-third of the patients $(25.7 \%)$, while only $2 \%$ used arterio-venous fistula. 
Common complications of dialysis include; hypotension which was present in $15.8 \%$, muscle cramp $6.9 \%$, rigor $13.9 \%$ and headache in $5 \%$. Over the period of review, 28 deaths were recorded while 44(43\%) patients were either lost to follow up or absconded and only 5\% with ESRD had living related kidney transplantation done at a referral centre as shown in figure 2.

Complications arising from vascular access were as follows; failed or difficult cannulation, poor flow, haematoma, bleeding, kinked catheter, thrombosis and infection. One patient had femoral vessel pseudoaneurysm from frequent cannulation.

Table 1: Clinical characteristics of patients

\begin{tabular}{|c|c|}
\hline Variable & Frequency (\%) \\
\hline Gender & \\
Males & $65(64.4)$ \\
Females & $36(35.6)$ \\
\hline Age categories (years) & \\
\hline 40 & $39(38.6)$ \\
$40-60$ & $39(38.6)$ \\
$>60$ & $23(22.8)$ \\
\hline Types of kidney disease & \\
AKI & $11(10.9)$ \\
\hline CKD & $90(89.1)$ \\
\hline Chronic glomerulonephritis & \\
\hline Hypertensive glomerusclerosis & $45(44.6)$ \\
Diabetic nephropathy & $26(25.7)$ \\
Obstructive Nephropathy & $15(14.9)$ \\
ADPKD & $4(4.0)$ \\
\hline Others & $2(2.0)$ \\
\hline
\end{tabular}

$\mathrm{AKI}=$ Acute Kidney Injury; $\mathrm{CKD}=$ Chronic Kidney Disease; $\mathrm{ADPKD}=$ Adult Polycystic Kidney Disease

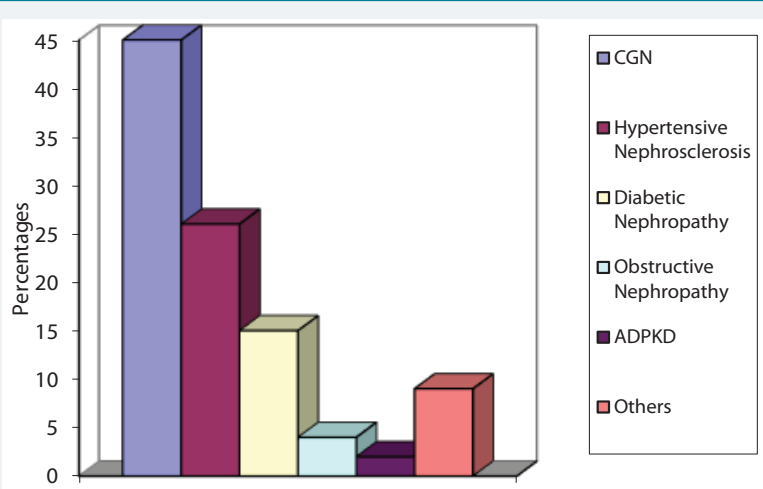

Figure 1: Distribution of aetiology of chronic kidney disease.

CGN = Chronic Glomerusclerosis; ADPKD = Adult Polycystic Kidney Disease; Others = Analgesic nephropathy; Sickle cell nephropathy; AKI that progress to CKD and unknown aetiology.

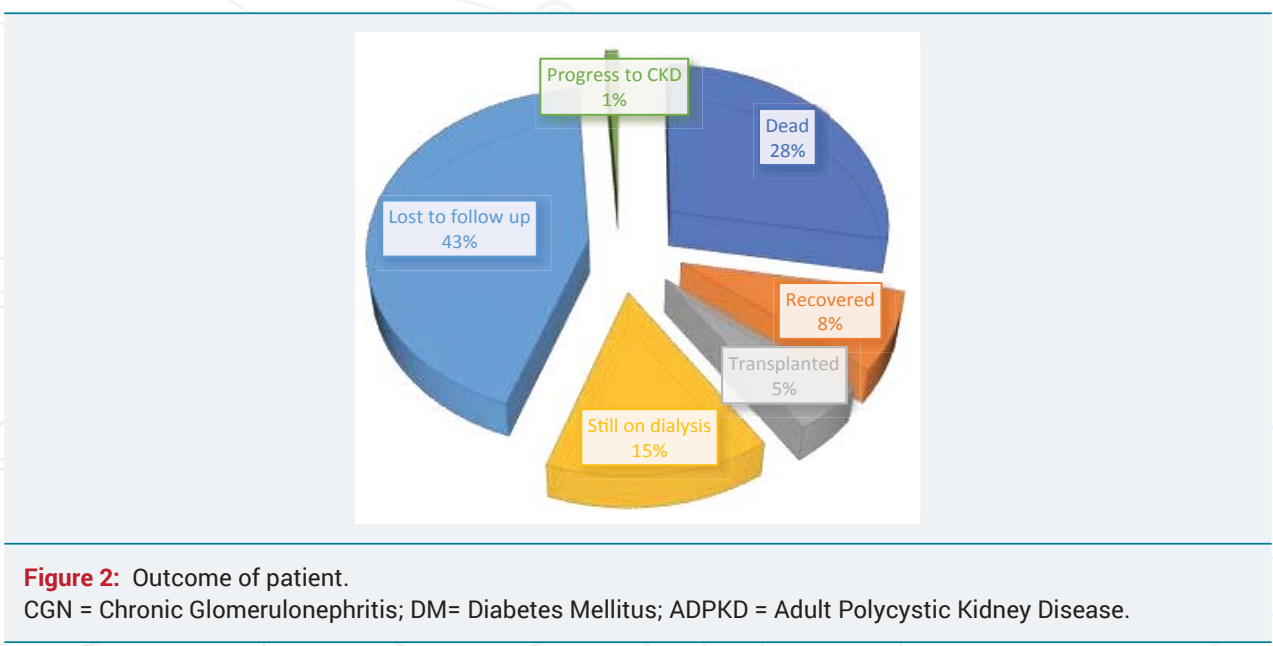




\section{Discussion}

Over the years of operation, there have been several challenges in the management of patients with kidney disease. Majority of the challenges stemmed from poor financial constraints experienced by our patients. Despite the lower cost of dialysis in our centre compared to other centres in the geopolitical zone, many patients still find it very difficult to start or even continue the therapy after a few sessions. Studies from SubSaharan Africa and other parts of our country reported that challenges encountered by patients on haemodialysis were a combination of several factors including cost of dialysis and trained personnel $[1,5]$.

Chronic glomerulonephritis as seen in $44.6 \%$ was the commonest aetiology cause of CKD among our patients. This is similar to the report of Oluyombo et al., and Okaka et al. [6,7], but in contrast to the findings of Bello et al., who reported hypertension as the cause of CKD in about half of their patient population [8]. Majority of our patients with chronic kidney disease presented very late with established complications. Late referral has been associated with complications that are uncommon among patients that were referred early. A retrospective study by Alebiosu found that more than two third $(77.8 \%)$ of their patients presented with various complications due to late referral [9].

The type and frequency of complications seen among our patients were similar to the report from other studies. A Cameroonian study [10], reported that hypotension and hypertensive crisis occurred respectively in $25 \%$ and $14 \%$ among their haemodialysis patients. Similarly, Okunola et al., observed that intradialytic hypotension was frequently seen among their dialysis patient [11].

Very few (2\%) patients had permanent vascular access. This is due to non-availability of vascular surgeon in our centre and the financial implication involved in creating this type of access at another distant nephrology centre where they could be referred is usually burdensome to the patient. The very low frequency of use of permanent access for haemodialysis in our centre is not too different from other centres in the country. Ekrikpo et al., documented that only 7 (7.4\%) of their patients had permanent access, while majority (92.6\%) were dialyzed through femoral veins [5]. In contrast to the commonest access route in our study, an Ethiopia study reported that about $45.1 \%$ of the patients on dialysis had arteriovenous (AV)-fistula. [12], Mtika et al. [13], reported that more than $95 \%$ of their CKD patients had internal jugular catheters while very few had subclavian vein cannulation and only one patient was reported to have femoral cannulation. This contrast is due to the cost and lack of expertise to create permanent access route in an economically challenged part of the world where this study was done. Though the practice is changing as more centres are now using tunneled jugular catheter and arteriovenous fistula. Infection was found to be a common cause of morbidity and mortality, this may be due to the increase in the use of indwelling catheter as compared to graft or fistula for vascular access, as this has been associated with reduced patient's survival $[12,14]$.

Haemodialysis is expensive and it is disproportionately affordable to a very few patients. A session of the procedure cost an average of \$75-150. None of our patients was able to maintain 3 sessions per week for up to three months as therapy is usually discontinued prematurely. This grossly fell short of the recommended target as outlined by Kidney Disease Outcomes Quality Initiative (KDOQI) [15]. Similarly, an unacceptable low number of patients having inadequate frequency of dialysis was documented by other researchers $[5,8,16]$. Almost all our patients paid out of pocket without any financial aids from the government hence they could not cope with the cost implication of dialysis. Inadequate dialysis and long interval between dialysis has been shown by several observational studies to increase morbidity and mortality risk [17-20] and lower the quality of life [18]. 
Affordability of the common medications such as antihypertensives, iron sucrose and/or erythropoiesis-stimulating agents is equally poor. Likewise, necessary biochemical profile for monitoring and evaluation of patients could not be done regularly due to financial cost. This created management challenge as decision to alter treatment became difficult in the absence of laboratory investigation to support such decision.

A high percentage (43.6\%) of patients were lost to follow up during this period due to reasons which may not be unrelated to financial constraints, traditional belief, and concept about the disease among others. A similar figure was reported by Meremo et al. in Tanzania [16] and Bello et al. in a Nigerian study [8]. Causes of death were inadequate dialysis due to financial constraints with its attendant complications, poor compliance to medication including antihypertensive, and sepsis among others.

\section{Conclusion}

Management of patients with chronic kidney disease in low resource countries is challenging. Successful RRT programmes are anchored on adequate government support. We therefore encourage more preventive measures to stem the upsurge of chronic kidney disease in this part of the world. Furthermore, we recommend that health caregivers should identify individuals at risk with the aim of prompt treatment, adequate counselling and early referral to the nephrologist. Establishment of early detection programmes for the general population to increase awareness of the kidney disease is equally advocated.

\section{References}

1. Naicker S. Nephrology in Africa - challenges of practice in resource-limited environment. Clin Nephrol. 2016; 86: 84-89. Ref.: https://goo.gl/WEmk2g

2. Okafor UH, Ekwem I, Wokoma FS. Challenges of kidney care in a resource poor nation: A study of private kidney care centre in Nigeria. Niger Med J. 2012; 53: 47-50. Ref.: https://goo.gl/GNkpyb

3. Stanifer JW, Jing B, Tolan S, Helmke N, Mukerjee R, et al. The epidemiology of chronic kidney disease in sub-Saharan Africa: a systematic review and meta-analysis. Lancet. 2014; 2: 174-181. Ref.: https://goo.gl/S8Dqgr

4. Couser WG, Remuzzi G, Mendis S, Tonelli M. The contribution of chronic kidney disease to the global burden of major noncommunicable diseases. Kidney Int. 2011; 80: 1258-1270. Ref.: https://goo.gl/JS2G3w

5. Ekrikpo UE, Udo Al, Ikpeme EE, Effa EE. Haemodialysis in an emerging centre in a developing country: a two year review and predictors of mortality. BMC Nephrol. 2011; 12: 50. Ref.: https://goo.gl/dBX7KB

6. Okaka El, Unuigbe El. Eight year review of hemodialysis: treated patients in a tertiary center in Southern Nigeria. Ann Afri Med. 2014; 13: 221-225. Ref.: https://goo.gl/7yohq6

7. Oluyombo R, Okunola OO, Olanrewaju TO, Soje MO, Obajolowo OO, et al. Challenges of hemodialysis in a new renal care center: call for sustainability and improved outcome. Int J Nephrol Renovasc Dis 2014; 7: 347-352. Ref.: https://goo.gl/RexUmP

8. Bello BT, Raji YR, Sanusi I, Braimoh RW, Amira OC, et al. Challenges of providing maintenance hemodialysis in a resource poor country: Experience from a single teaching hospital in Lagos, Southwest Nigeria. Hemodial Int. 2013; 17: 427-433. Ref.: https://goo.gl/xscLWy

9. Alebiosu CO. Detrimental effects of late referral for dialysis. Afr J Health Sci. 2001; 8: 89-92. Ref.: https://goo.gl/cwAZSz

10. Kaze FF, Ashuntantang G, Kengne AP, Hassan A, Halle MP, et al. Acute hemodialysis complications in end-stage renal disease patients: the burden and implications for the under-resourced Sub-Saharan African health systems. Hemodial Int. 2012; 16: 526-531. Ref.: https://goo.gl/SUqcQt

11. Okunola $Y$, Ayodele $O$, Akinwusi $P$, Gbadegesin $B$, Oluyombo R. Haemodialysis practice in a resourcelimited setting in the tropics. Ghana Med J. 2013; 47: 4-9. Ref.: https://goo.gl/hLcbec

12. Shibiru T, Gudina EK, Habte B, Deribew A, Agonafer T. Survival patterns of patients on maintenance hemodialysis for end stage renal disease in Ethiopia: summary of 91 cases. BMC Nephrol. 2013; 14 : 127. Ref.: https://goo.gl/b6AmNH 
13. Mtika V, Muula A, Chipolombwe J, Nyirongo J, Rajabu J. Renal replacement therapy at lilongwe Central Hospital, Malawi. Trop Doc. 2002; 32: 163-165. Ref.: https://goo.gl/gh91S5

14. Krzanowski M, Janda K, Chowaniec E, Kusnierz-Cabala B, Sulowicz W. [Types of hemodialysis vascular access in patients on renal replacement therapy and its complications during a one year observation period]. Przegl Lek. 2011; 68: 343-347. Ref.: https://goo.gl/c72Cw6

15. National Kidney Foundation. KDOQI Clinical Practice Guideline for Hemodialysis Adequacy: 2015 Update. Am J Kidney Dis. 2015; 66: 884-930. Ref.: https://goo.gl/WAQDXJ

16. Meremo AJ, Ngilangwa DP, Mwashambwa MY, Masalu MB, Kapinga J, et al. Challenges and outcomes of haemodialysis among patients presenting with kidney diseases in Dodoma. Tanzania. BMC Nephrol. 2017; 18: 212. Ref.: https://goo.gl/RzRVPA

17. Acchiardo SR, Hatten KW, Ruvinsky MJ, Dyson B, Fuller J, et al. Inadequate dialysis increases gross mortality rate. ASAIO J. 1992; 38: M282-M285. Ref.: https://goo.gl/o13YPt

18. Chauhan R, Mendonca S. Adequacy of twice weekly hemodialysis in end stage renal disease patients at a tertiary care dialysis centre. Indian J Nephrol. 2015; 25: 329-333. Ref.: https://goo.gl/cRBnJc

19. Tentori F, Zhang J, Li Y, Karaboyas A, Kerr P, et al. Longer dialysis session length is associated with better intermediate outcomes and survival among patients on in-center three times per week hemodialysis: results from the Dialysis Outcomes and Practice Patterns Study (DOPPS). Nephrol Dial Transplantant. 2012; 27: 4180-4188. Ref.: https://goo.gl/pz6TVz

20. Marshall MR, Byrne BG, Kerr PG, McDonald SP. Associations of hemodialysis dose and session length with mortality risk in Australian and New Zealand patients. Kidney Int. 2006; 69: 1229-1236. Ref.: https://goo.gl/bPVQ1x 